\title{
Forecasting the length-of-stay of pediatric patients in hospitals: a scoping review
}

\author{
Natália B. Medeiros ${ }^{1}$, Flavio S. Fogliatto ${ }^{1 *}$, Miriam K. Rocha ${ }^{2}$ and Guilherme L. Tortorella $a^{3,4,5}$
}

\begin{abstract}
Background: Healthcare management faces complex challenges in allocating hospital resources, and predicting patients' length-of-stay (LOS) is critical in effectively managing those resources. This work aims to map approaches used to forecast the LOS of Pediatric Patients in Hospitals (LOS-P) and patients' populations and environments used to develop the models.

Methods: Using the Preferred Reporting Items for Systematic reviews and Meta-Analyses extension for Scoping Reviews (PRISMA-SCR) methodology, we performed a scoping review that identified 28 studies and analyzed them. The search was conducted on four databases (Science Direct, Scopus, Web of Science, and Medline). The identification of relevant studies was structured around three axes related to the research questions: (i) forecast models, (ii) hospital length-of-stay, and (iii) pediatric patients. Two authors carried out all stages to ensure the reliability of the review process. Articles that passed the initial screening had their data charted on a spreadsheet. Methods reported in the literature were classified according to the stage in which they are used in the modeling process: (i) pre-processing of data, (ii) variable selection, and (iii) cross-validation.

Results: Forecasting models are most often applied to newborn patients and, consequently, in neonatal intensive care units. Regression analysis is the most widely used modeling approach; techniques associated with Machine Learning are still incipient and primarily used in emergency departments to model patients in specific situations.

Conclusions: The studies' main benefits include informing family members about the patient's expected discharge date and enabling hospital resources' allocation and planning. Main research gaps are associated with the lack of generalization of forecasting models and limited reported applicability in hospital management. This study also provides a practical guide to LOS-P forecasting methods and a future research agenda.
\end{abstract}

Keywords: Hospital length-of-stay, Forecasting models, Pediatric patients, Neonatal patients, Scoping review

\section{Background}

With the increasing demand for health services, hospitals worldwide are operating under pressure to increase patient care quality while ensuring organizational survival [1]. The hospital environment is complex and imposes several managerial challenges related to optimal utilization of limited resources and the constant need to improve efficiency and reduce patients' length-of-stay

\footnotetext{
* Correspondence: ffogliatto@producao.ufrgs.br

'Department of Industrial Engineering, Universidade Federal do Rio Grande do Sul, Av. Osvaldo Aranha, 99, $5^{\circ}$ andar, Porto Alegre 90035-190, Brazil

Full list of author information is available at the end of the article
}

(LOS) [2]. Resource utilization planning requires predicting patients' LOS since longer times imply lower turnover and higher costs, affecting the quality of patient care and reducing the availability of services to the population [3].

Forecasting pediatric patients' LOS (LOS-P) in hospitals is particularly important since pediatric departments constantly struggle with capacity and overcrowding restrictions $[2,4]$, which could be avoided by predicting the use of hospital resources, and better dimensioning of care and hospitalization capacity [5]. In addition, forecasting LOS-P allows hospital managers to inform family

(c) The Author(s). 2021 Open Access This article is licensed under a Creative Commons Attribution 4.0 International License which permits use, sharing, adaptation, distribution and reproduction in any medium or format, as long as you give appropriate credit to the original author(s) and the source, provide a link to the Creative Commons licence, and indicate if changes were made. The images or other third party material in this article are included in the article's Creative Commons licence, unless indicated otherwise in a credit line to the material. If material is not included in the article's Creative Commons licence and your intended use is not permitted by statutory regulation or exceeds the permitted use, you will need to obtain permission directly from the copyright holder. To view a copy of this licence, visit http://creativecommons.org/licenses/by/4.0/ The Creative Commons Public Domain Dedication waiver (http://creativecommons.org/publicdomain/zero/1.0/) applies to the data made available in this article, unless otherwise stated in a credit line to the data. 
members about the patient's expected discharge date. We identified in the literature five dimensions positively affected by the use of forecasting models, which are presented in detail in the Discussion section; they are: $(i)$ patient care, (ii) costs, (iii) hospital management, (iv) quality measurement, and (v) updating of medical practices.

Forecasting patients' LOS is a subject widely studied in the literature through different methods and applications. Some studies use simple methods such as linear regression analysis (e.g., [6]), while more current studies use artificial intelligence techniques based on machine learning and deep learning (e.g., [7]). Literature review studies devoted to forecasting patients' LOS in hospitals mainly analyze the adult population. Almashrafi et al. [8] and Peres et al. [9] conducted systematic literature reviews to find predictors of patients' LOS in hospitals that should be considered in the generation of forecasting models. Atashi et al. [10], Hussain and Dunn [11], Lu et al. [12], and Verburg et al. [13] focused their reviews on the quality of the models proposed in the literature aiming at establishing a benchmark. Seaton et al. [14] was the only literature review that analyzed the pediatric population, identifying important factors when predicting neonates' LOS in neonatal units.

In this article, we present a scoping review of the literature on LOS-P forecasting, addressing the current lack of studies that analyze the existing theoretical framework on the topic and map the main approaches used in the generation of LOS-P forecasting models. We present the main modeling techniques, their benefits and limitations, the environments investigated, and the types of pediatric populations considered. We close the article by presenting practical implications and directions for future research.

\section{Methods}

The research method follows the methodology proposed by Arksey and O'Malley [15], which comprises five steps: (i) identification of research questions, (ii) identification of relevant studies, (iii) selection of studies, (iv) mapping of the data, and $(v)$ collection, summarization, and reporting of the results. These steps are subsequently detailed. Scoping reviews provide a transparent and rigorous mapping of a research area, producing an accessible summary of the research results and indicating the existing gaps [15]. Scoping reviews are suitable for topics with scarcity of studies and whose body of knowledge has not been consolidated through a systematic literature review.

This research was driven by elements related to the forecasting of LOS-P, namely: techniques used, environments and populations in which techniques were applied, and results generated by the models created.
Based on these elements, the study addressed five research questions:

$\mathbf{R Q}_{\mathbf{1}}$. What are the main techniques used to forecast LOS-P?

$\mathbf{R Q}_{\mathbf{2}}$. In which situations are those techniques applied?

$\mathbf{R Q}_{3}$. What are the main characteristics of the data used to predict LOS-P?

$\mathbf{R Q}_{\mathbf{4}}$. What are the managerial implications of using LOS-P forecasting models for resource management in hospitals?

$\mathbf{R Q}_{\mathbf{5}}$. What are the main barriers and limitations of the existing studies and opportunities for future research?

The identification of relevant studies was structured around three axes related to the research questions: $(i)$ forecast models, (ii) hospital length-of-stay, and (iii) pediatric patients. Those axes led to a combination of keywords used in the search (Table 1) and the research strategies used in each database in Supplementary Material 1. Four databases were consulted: Science Direct, Scopus, Web of Science, and Medline. The first three bases were chosen following the recommendation of Tortorella et al. [16]. The inclusion of Medline was due to its recurrent use in review articles on hospital LOS forecasting, e.g., [11, 13, 14]. The first axis should be present in the title, abstract, or keywords in our search, while the second and third axes should be present only in the title. The search was carried out between August 27 and September 11, 2020, using the CAPES platform (https://www.periodicos.capes.gov.br), which is a unified platform provided by the Brazilian Ministry of Education. We selected journal or conference articles published in English with no restriction with respect to publication date, resulting in a total of 821 articles. We did not consider $(i)$ studies not yet been published or published as pre-prints due to the possibility that they may eventually not comply with the quality requirements of peer-reviewed journals and conferences, and $(i i)$ conference abstracts and clinical tests, since they lacked sufficient information for the analysis.

To conduct the selection of studies, we followed the guidelines of Preferred Reporting Items for Systematic reviews and Meta-Analyses extension for Scoping Reviews (PRISMA-ScR )[17], as displayed in Fig. 1. The first two authors primarily carried out all stages to ensure the reliability of the review process. Differences in opinions were discussed with the remaining authors to reach a consensus. After this screening, data charting was done by the main author using an electronic spreadsheet; discrepancies discovered at this stage were addressed by all authors.

The identification stage was performed by searching for the axes in the chosen databases. The screening stage 
Table 1 Research axes and keywords

\begin{tabular}{|c|c|c|c|}
\hline Research axes & Forecast models & Length of stay in hospital & Pediatric patients \\
\hline \multirow[t]{9}{*}{ Keywords } & Predict $^{a}$ & "Length of Stay" & Child $^{a}$ \\
\hline & Model & "Hospital Days" & Pediatric \\
\hline & Prognos $^{a}$ & "Length of Hospital Stay" & Paediatric \\
\hline & Forecast $^{a}$ & "Duration of Stay" & Kid \\
\hline & Regression & "Patient Stay" & Youth $^{\mathrm{a}}$ \\
\hline & Estimat $^{\mathrm{a}}$ & & Adolescen $^{a}$ \\
\hline & & & Neonat ${ }^{a}$ \\
\hline & & & Newborn ${ }^{a}$ \\
\hline & & & Infant ${ }^{a}$ \\
\hline
\end{tabular}

${ }^{a}$ is used so that the search returns all terms that begin with the word followed by the asterisk. Enclosing a sentence in double-quotes ensures that the search returns only documents in which the sentence appears and not just the words in any order

included two filters: $(i)$ exclusion of duplicates and (ii) inclusion/exclusion criteria. The first filter excluded 528 duplicates; 293 publications remained. The remaining articles' titles and abstracts were verified according to the second filter's inclusion/exclusion criteria.

To be included in this review, studies (i.e., concept) should develop mathematical models to predict patients' LOS in hospitals (i.e., context), and the studied population should be pediatric patients (i.e., population). Publications were excluded when the dependent variable was not the LOS in hospitals or investigated the effects of individual factors on LOS-P. After applying the inclusion/ exclusion criteria, 44 articles remained. The eligibility stage consisted of a full-text analysis identifying articles aligned with the proposed research questions, resulting in 26 articles. In the final stage (inclusion), the selected articles' references were checked to identify studies potentially aligned with the research theme and not identified during searches in the selected databases. Based on this backward snowballing technique, two articles were

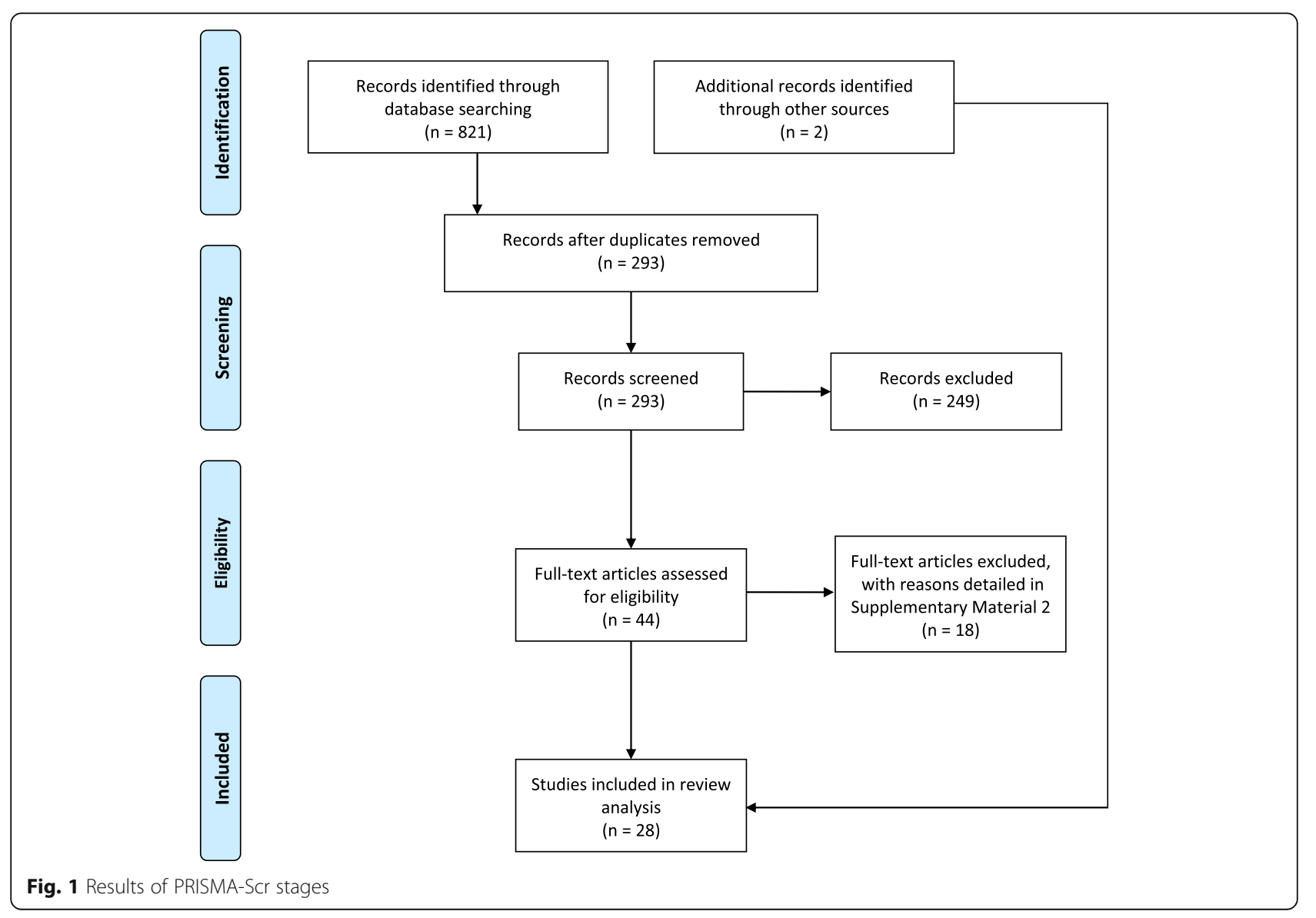


included totaling 28 publications in the final corpus. All articles were published in peer-reviewed journals and conferences, as informed on their webpages.

According to Arksey and O'Malley [15], data mapping must extract key information from the studies reviewed to help readers make decisions. We used the descriptiveanalytical method to build an analytical structure, collecting standard information about each study. The following information was retrieved from our corpus, allowing the mapping of the literature: authors, year of publication, country of origin of the first author, journal or conference title, area of knowledge of the publication, application focus (i.e., department and population), data characteristics, techniques used to build the forecast model, limitations, contributions, future research directions (see Supplementary Material 3). We used the information extracted during the data mapping to group, summarize, and present the results in a logical and organized way, answering the research questions.

We prepared an overview of the selected studies based on a descriptive numerical summary and thematic analysis [15]: the summary provided a quantitative view of the articles' main characteristics, while the analysis allowed a qualitative view of the articles and in-depth insights regarding the literature. That provided means to complement the descriptive numerical summary trends, contributing to fully answer our research questions.

\section{Results}

Our corpus of works on LOS-P forecasting contains mostly journal papers (89\%) authored by 125 authors who contributed to the topic with only one publication. Studies appeared in the proceedings of 3 conferences and 21 different journals, two of which with more than one publication: Journal of Perinatology $(n=2)$ and Journal of the American Academy of Child \& Adolescent Psychiatry $(n=2)$. Research took place in nine different countries, four of which with more than one publication: USA $(n=17)$, Germany $(n=2)$, Brazil $(n=2)$, and Canada $(n=2)$. Studies belong to several knowledge areas (with prevalence in Pediatrics, $n=8$, and Psychiatry, $n=4$ ), medical specialties (e.g., cardiology and neurology), and medical departments (e.g., emergency and intensive care). Only one study is in the area of Computer Science, indicating that research on LOS-P prediction emphasizes healthcare applications rather than forecasting methods. The evolution of publications per year shows an increase in studies over the decades, beginning in the 1980s $(n=1)$ and with the most recent publications in $2020(n=2)$. In the decades of $1990(n=6), 2000(n=9)$, and $2010(n=10)$, the number of studies increased considerably, bending towards the use of Machine Learning modeling techniques.
In the thematic analysis, we divided studies according to three dimensions: the technical approach used to generate the forecasts, the medical department where the study took place, and the population analyzed. Table 2 summarizes our findings and serves as a guide to what has already been reported in the literature, addressing $R Q_{1}$ and $R Q_{2}$.

The technical approaches were divided into Regression Analysis (used in 75\% of the studies), Machine Learning techniques, and Others. Departments where studies took place were divided into six categories, one of which including articles that did not convey that information. The largest number of studies took place in Neonatal Intensive Care units (39.29\%) and Psychiatric units or hospitals $(21.43 \%)$, which are highly controlled areas with abundant LOS data. In those environments, regression analysis was the predominant forecasting technique. In opposition, LOS data from Emergency departments were exclusively modeled using Machine Learning techniques. Regarding the population analyzed, most studies used data from newborn patients $(42.86 \%)$ or patients in specific situations (28.57\%), e.g., victims of ATV accidents and children with hematologic malignancies complicated by febrile neutropenia. Fewer studies (32\%) involved adolescent patients or young adults.

Table 3 characterizes the datasets used in the studies, addressing $R Q_{3}$. The information in the table was collected through a critical appraisal of the corpus of articles, which was performed informally and without the aid of any specific tool.

Hospitalizations of pediatric patients were sampled in 13 countries; the USA $(n=14)$ is the country with the highest representation in the studies (50\%). Data were collected between 1987 and 2017, covering from 9 to 120 months; data were mainly collected during the 1990s $(n=10)$ and 2000s $(n=10)$. Four studies do not specify the sampling period; the majority performed the sampling in a period equal to or greater than 1 year $(n=22)$. Sample sizes range from 41 to 23,551 observations. Most studies $(n=15)$ took place at a single location, indicating a low concentration of multicenter studies. Studies' LOS $-P$ values display averages or medians ranging from 3.39 days to 18.02 months, with more than $40 \%$ of the articles not reporting this information $(n=12)$. The longest LOS occurred in hospitals or Psychiatric units (ranging from 2 to 18 months). In Neonatal Intensive Care units, LOS-P averages vary from 23 to 54.8 days, with the highest averages (54.8 and 52.8 days) concentrated in the population of very low-weight neonates.

References: [32] Anderson et al. (2009) [42]; Balan et al. (2019) [29]; Bannwart et al. (1999) [27]; bender et al. (2012) [38]; Browning (1986) [35]; gold et al. (1993) [21]; Hintz et al. (2009) [36]; Höger et al. (2002) [22]; Jeremic and $\tan$ (2008) [34]; Kavanaugh et al. 
Table 2 Summary of studies regarding forecasting approach, and investigated department and population

\begin{tabular}{|c|c|c|c|c|c|}
\hline \multirow[t]{2}{*}{ Department } & \multirow[t]{2}{*}{ Population } & \multicolumn{3}{|l|}{ Approach } & \multirow{2}{*}{$\begin{array}{l}\text { \# of } \\
\text { articles }\end{array}$} \\
\hline & & Regression & $\begin{array}{l}\text { Machine } \\
\text { Learning }\end{array}$ & Others & \\
\hline \multirow[t]{2}{*}{ Emergency } & Babies and children with bronchiolitis & & [18] & & 2 \\
\hline & Pediatric trauma patients & & [19] & & \\
\hline \multirow{3}{*}{$\begin{array}{l}\text { Neonatal Intensive Care } \\
\text { units }\end{array}$} & Premature newborns & [20-22] & & & 11 \\
\hline & Newborns & [23-26] & & [27] & \\
\hline & Chronically underweight newborns & [28-30] & & & \\
\hline $\begin{array}{l}\text { Pediatric Intensive Care } \\
\text { units }\end{array}$ & Pediatric patients & [31] & & & 1 \\
\hline \multirow[t]{3}{*}{ Pediatric unit or hospital } & Babies undergoing bidirectional Glenn procedure & [32] & & & 3 \\
\hline & $\begin{array}{l}\text { Children with hematological diseases complicated by febrile } \\
\text { neutropenia }\end{array}$ & [33] & & & \\
\hline & Pediatric patients with respiratory diseases & & {$[2]$} & & \\
\hline \multirow[t]{3}{*}{ Psychiatric unit or hospital } & Children & {$[3,34,35]$} & & [36] & 6 \\
\hline & Teenagers & {$[3,37,38]$} & & [36] & \\
\hline & Young Adults & {$[38]$} & & & \\
\hline \multirow[t]{5}{*}{ Not specified } & Premature newborns & [39] & [39] & & 5 \\
\hline & Newborns and babies undergoing cardiac surgery & {$[40]$} & & & \\
\hline & Babies admitted for gastroenteritis & [41] & & & \\
\hline & Pediatric patients & & {$[42]$} & & \\
\hline & Pediatric victims of ATV accidents & [43] & & & \\
\hline$N^{0}$ of articles & & 21 & 5 & 2 & \\
\hline
\end{tabular}

(2019) [24]; Khoshnood et al. (1996) [41]; lee et al. (2005) [26]; lee et al. (2016) [3]; Leon et al. (2006) [31]; Levin et al. (2012) [2]; ma et al. (2020) [30]; Marshall et al. (2012) [43]; Nagarsheth et al. (2011) [40]; Parkman and woods (2005) [33]; Pastura et al. (2004) [20]; Paul et al. (2020) [25]; Pearlman et al. (1992) [23]; Pepler et al. (2012) [28]; Rendina (1998) [37]; Stewart et al. (2013) [19]; Walczak and Scorpio (2000) [18]; Walsh et al. (2004) [39]; Zernikow et al. (1999)

Methods used to build the forecasting models are divided into three groups, according to the stage of model development they propose to address: (i) pre-processing, which prepares the data prior to modeling (see Table 4); (ii) variable selection, which optimizes the forecasting model by improving its precision and interpretability using the most informative variables (see Table 5); and (iii) cross-validation, which evaluates the performance of the model in different datasets (see Table 6). Several statistical and machine learning methods are proposed at each stage of model development, with references to works using each method listed in Tables 4, 5 and 6. In general, the reader does not have to search beyond those references to gather basic information on the methods. However, an overview of statistics-based methods is available in Kotz et al. [44] and machine learning-based methods in Bishop [45].
The pre-processing methods reported in our corpus may be divided into $(i)$ data cleaning methods to avoid modeling noise and (ii) methods to prepare and transform data to remove scale effects. The primary preprocessing method for data cleaning is the collinearity test, which evaluates the correlation level between independent variables. The test was reported in eight studies. To avoid noise in the model due to the excessive number of observations with missing data in the independent variables, six studies excluded incomplete observations from the datasets, and two adopted data imputation strategies. Two studies mention the withdrawal of outliers from the datasets before modeling.

The main pre-processing method for data transformation, adopted in ten studies, is the logarithmic transformation of LOS $-P$ values to correct the positive asymmetric distribution of the dependent variable. The logarithmic transformation also reduces the effect of outliers, ensuring the residuals' normality and stabilizing the variance.

Eight studies treat categorical variables as dummy variables or use specific codings that vary according to needs. Two studies use data rescaling through normalization and linear transformation. Other data preparation methods include the categorization of variables and feature engineering, which creates new variables by combining the ones available in the dataset. 
Table $\mathbf{3}$ Characteristics of datasets used in the studies

\begin{tabular}{|c|c|c|c|c|c|}
\hline Reference & Country & Sampling period & $\begin{array}{l}\text { Sample } \\
\text { size }\end{array}$ & Hospitals & LOS-P \\
\hline [32] & USA & July 2001 to December 2007 & 100 & 1 & Median: 20 days \\
\hline [42] & USA & 2016 & 5236 & 4200 & Not informed \\
\hline [29] & Not informed & January 1992 to December 1993 & 97 & 1 & Mean: 52.8 days \\
\hline [27] & USA & $\begin{array}{l}\text { August } 1999 \text { to October 1999, and April } 2002 \text { to } \\
\text { September } 2002\end{array}$ & 908 & 1 & Not informed \\
\hline [38] & Not informed & Not informed & 41 & 1 & $\begin{array}{l}\text { Mean: } 18.02 \\
\text { months }\end{array}$ \\
\hline [35] & USA & May 1988 to December 1989 & 96 & 1 & Mean: 71.6 days \\
\hline [21] & USA & July 2002 to December 2005 & 2254 & $\begin{array}{l}\text { Not } \\
\text { informed }\end{array}$ & Not informed \\
\hline [36] & Germany & Not informed & 1001 & 13 & $\begin{array}{l}\text { Median: } 104 \\
\text { days }\end{array}$ \\
\hline [22] & Canada & Not informed & 186 & 1 & Not informed \\
\hline [34] & Not informed & 2010 to 2015 & 96 & 1 & $\begin{array}{l}\text { Mean: } 18.56 \\
\text { days }\end{array}$ \\
\hline [24] & USA & 1990 & 558 & 1 & Mean: 23 days \\
\hline [41] & Australia & 1995 & 514 & 58 & Mean: 3.39 days \\
\hline [26] & USA & 2008 to 2011 & 23,551 & 125 & Not informed \\
\hline [3] & USA & 1998 to 2001 & 1930 & 44 & Mean: 10.4 days \\
\hline [31] & USA & Not informed & 2062 & 1 & Mean: 3.5 days \\
\hline [2] & China & January 2014 to April 2016 & 11,206 & 1 & Not informed \\
\hline [30] & $\begin{array}{l}\text { Argentina, Chile, Paraguay, Peru and } \\
\text { Uruguay }\end{array}$ & January 2001 to December 2008 & 7599 & 20 & Not informed \\
\hline [43] & USA & January 2000 to December 2009 & 420 & $\begin{array}{l}\text { Not } \\
\text { informed }\end{array}$ & Not informed \\
\hline [40] & Not informed & September 1993 to December 1997 & 458 & 1 & Not informed \\
\hline [33] & Brazil & February 2001 to May 2002 & 62 & 1 & Mean: 10 days \\
\hline [20] & USA & November 2014 to March 2017 & 152 & 14 & Not informed \\
\hline [25] & USA & October 1987 to July 1988 & 393 & 1 & Mean: 23.8 days \\
\hline [23] & South Africa & January 2007 to December 2008 & 3794 & 15 & Mean: 17.9 days \\
\hline [28] & USA & January 1994 to December 1996 & 314 & 2 & Mean: 54.8 days \\
\hline [37] & Canada & October 2005 to March 2010 & 2445 & 69 & $\begin{array}{l}\text { Mean: } 16.31 \\
\text { days }\end{array}$ \\
\hline [19] & USA & April 1994 to December 1997 & 7665 & $\begin{array}{l}\text { Not } \\
\text { informed }\end{array}$ & Mean: 3.98 days \\
\hline [18] & Ireland & 1999 & 119 & 1 & Not informed \\
\hline [39] & Not informed & October 1989 to January 1996 & 2144 & 1 & Not informed \\
\hline
\end{tabular}

Regarding the variable selection methods, most studies $(n=17)$ propose reducing the number of variables in the model to keep only the most informative. Variable selection aims to balance model simplicity and performance; however, it is noteworthy that most Machine Learningbased studies do not use any variable selection method (except for Zernikow et al. [39], who proposes the Forward Stepwise method). The most popular variable selection methods are the Analysis of Variance and the variable significance test.
Three studies use the stepwise backward method, which starts with all variables in the model and removes at each iteration the least significant one. Three studies use the stepwise forward method, starting with a model with no variables and adding the most significant one at each iteration. In addition to the methods mentioned above, others less predominant in the studies are correlation analysis, stepwise multiple Cox regression, and Principal Component Analysis (PCA). 


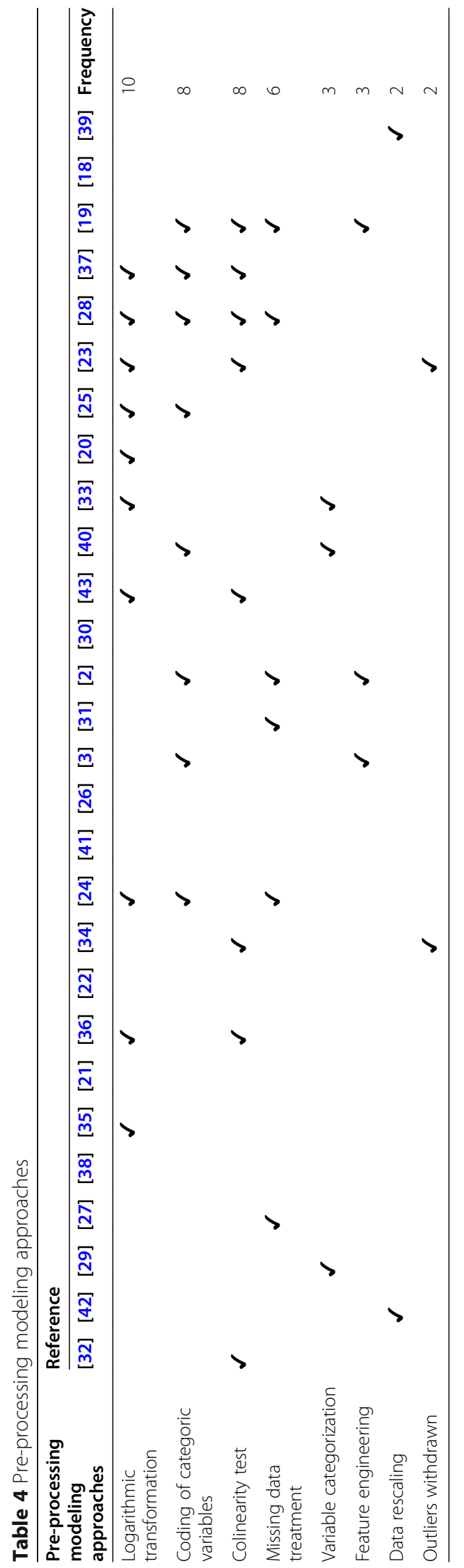




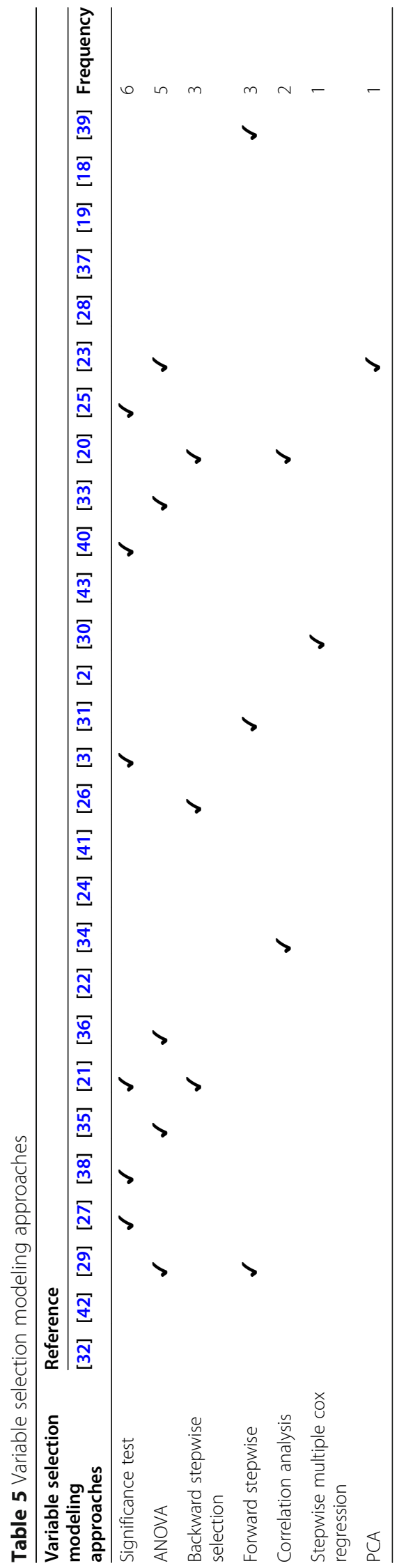




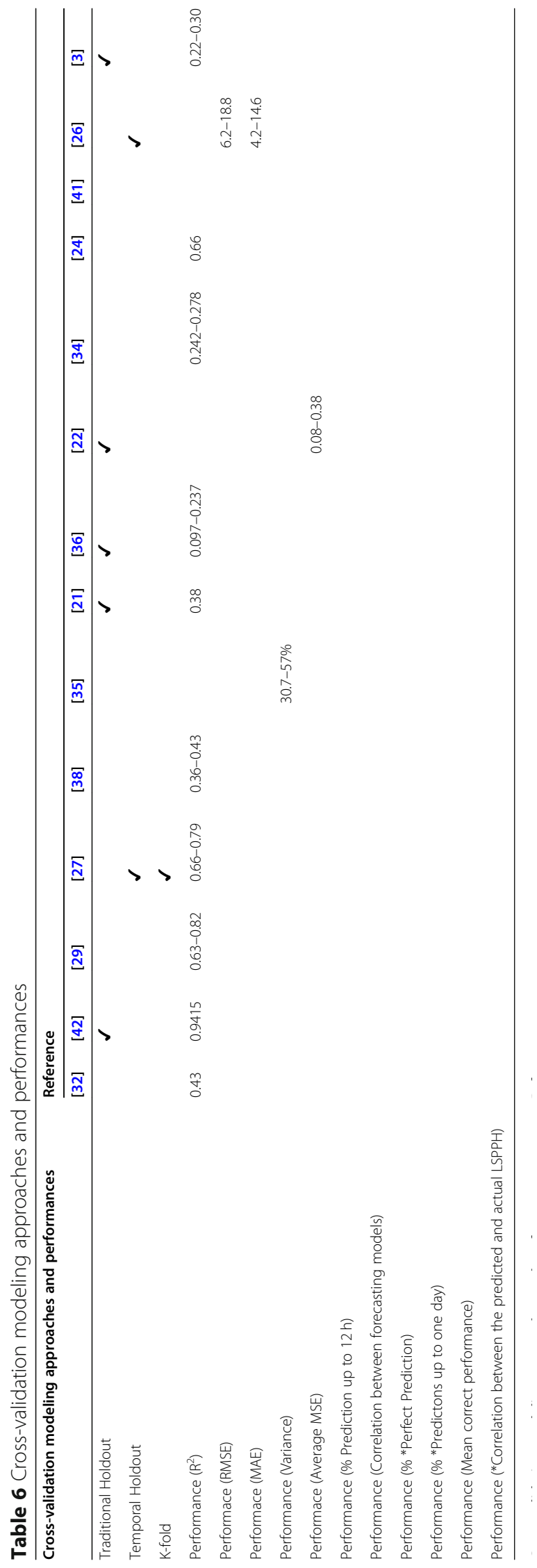




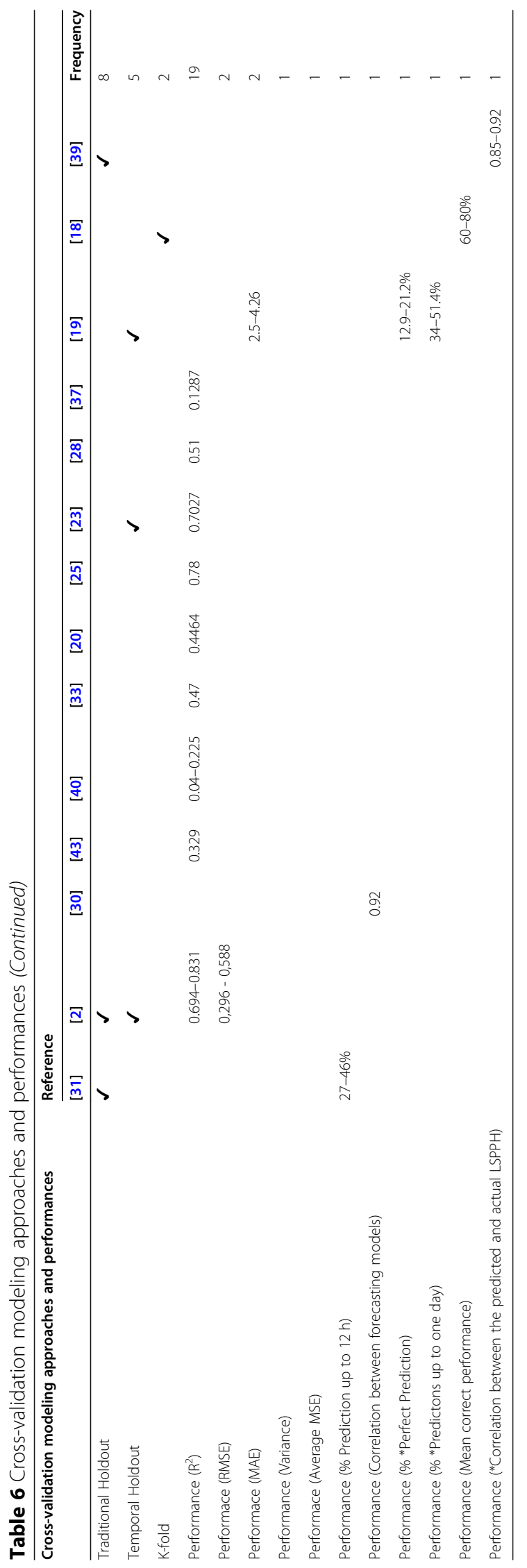


Half of the studies in our corpus use cross-validation to validate model results, seeking its generalization. Cross-validation approaches are divided into three categories: traditional holdout, temporal holdout, and $k$ fold. The holdout method divides the dataset into two partitions (training and testing), which are mutually exclusive and vary according to the analyst's preferences. Traditional holdout randomly splits the dataset, assuming that the frequency distributions do not change over time; temporal holdout divides the dataset taking into account the temporal evolution of the data. Except for two studies that do not mention the percentage of the dataset used in each partition [2, 30], all other studies use traditional holdout, varying the proportion of the dataset in the training and testing partitions as follows: $80-20 \%[31,42], 75-25 \%$ [39], 70-30\% [21], and 50-50\% [3, 36]. The $k$-fold method randomly divides the dataset into $k$ unique parts of the same size, trains the forecast model with $k-1$ parts, and uses the remaining part for validation. The process is repeated $k$ times, such that all parts are used in the validation step. Walsh et al. [18] use 5-fold, with the dataset divided into training, testing, and validation in five different ways, while Bender et al. [27] do not give details on the $k$-fold method used.

The performance of LOS-P forecasting models is measured using several metrics. The most used performance metric $(n=19)$ is the coefficient of determination $\left(R^{2}\right)$ that measures the proportion of the variability in the dependent variable captured by the model. In studies measuring model performance using $R^{2}$, values ranged from 0.04 to 0.9415 , with most studies reporting values greater than $0.5(n=8)$. Other performance metrics reported are the Root Mean Square Error (RSME) and the Mean Absolute Error (MAE). RMSE measures the standard deviation of model errors; studies that use this metric report values between 0.296 and 18.8 days $[2,26]$. MAE measures the absolute average value of the differences between forecasts and actual observations; studies that used this metric reported values between 2.5 and 14.6 days $[19,26]$.

The independent variables (descriptors) used to build the forecasting models differ greatly between the studies since they analyze different populations and departments. Most studies use patient demographic descriptors such as age (neonatal age, postmenstrual age, gestational age, and chronological age), gender, and race. Studies modeling newborn populations usually include weight at birth as descriptor in the models. Other variables commonly reported are related to patients' diagnoses, surgical procedures, and existing comorbidities. In addition, several studies use results from specific laboratory exams as descriptors in the prediction models (e.g., systolic blood pressure, respiratory rate, Apgar scores at 1 and 5 min, and neurocognitive presentation).
To start addressing $R Q_{5}$, we list the main limitations and barriers reported in the LOS-P forecasting literature. They are: (i) lack of model generalizability due to differences across hospitals, (ii) lack of data on potentially useful LOS-P predictors, (iii) small sample sizes used to obtain forecasting models, and (iv) studies based on samples that do not adequately represent the entire population.

\section{Discussion}

The analytical methods presented in Tables 4, 5 and 6 are not directly comparable since they are applied to different population samples, using various combinations of pre-processing, variable selection, and cross-validation approaches. However, our scoping review should help readers to identify which analytical pathways have been tested for specific populations and how they perform in terms of prediction. To identify works covering a certain population of interest and forecasting approach, the reader is directed to Table 2 , with details mapped in Tables 4, 5 and 6 .

The extensive utilization of regression analysis in LOS-P forecasting is aligned with findings in Hussain and Dunn [11], who reviewed studies that predicted LOS of thermal burned patients and reported that all forecasting models were based on multivariate regression analysis. We also reported a trend towards artificial intelligence-based forecasting models in recent years, which was not observed in previous review studies, e.g., Seaton et al. [14] reported only one model based on Artificial Neural Networks, while Almashrafi et al. [8] and $\mathrm{Lu}$ et al. [12] reported a model based on decision trees. The dependent variable used in all studies we reviewed was the continuous LOS; in opposition, Almashrafi et al. [8], Atashi et al. [10], Lu et al. [12], and Seaton et al. [14] presented studies that modeled the discrete LOS of patients using multivariate logistic regression.

In terms of the main pre-processing methods, regardless of the frequently observed positive asymmetric distribution of the LOS variable, only $35.7 \%$ of our reviewed studies used the logarithmic transformation, similar to what was reported by Lu et al. [12], in which $32 \%$ of studies used log-transformed LOS as the dependent variable. Most studies in our review did not mention the handling of missing data, a gap that was also reported by Atashi et al. [10].

Concerning the approaches for variable selection, reviews by Hussain and Dunn [11] and Peres et al. [9] reported that most studies selected variables to be included in the forecasting models through univariate analysis, while Seaton et al. [14] reported results similar to ours (i.e., analysis of variance and significance tests). Other authors did not report some variable selection 
techniques identified in our review (i.e., stepwise multiple Cox regression, correlation analysis, and Principal Components Analysis).

For cross-validation, previous reviews reported similar results to ours: Seaton et al. [14] concluded that over $50 \%$ of the authors investigated had validated results by splitting the sample, while Verburg et al. [13] reported that over $38 \%$ of the studies used simple random sample split. Bootstrapping cross-validation, an approach not identified in our studies, was mentioned by Atashi et al. [10] and Verburg et al. [13].

Regarding the performance of LOS-P forecasting models, the predominance of the coefficient of determination $\left(R^{2}\right)$ was also found in the studies reported by Seaton et al. [14] and Hussain and Dunn [11], with values ranging from 0.158 to 0.75 . In opposition, reviews by Atashi et al. [10] and Verburg et al. [13] found that Pearson's correlation coefficient was the preferred performance metric.

Most studies report benefits from using LOS-P forecasts for the hospital ecosystem. We identified five dimensions positively affected by the use of forecasting models: (i) patient care, (ii) costs, (iii) hospital management, (iv) quality measurement, and (v) updating of medical practices. The two main benefits reported in the patient care dimension are providing families information about the expected discharge date and preventing complications associated with prolonged hospitalizations. Hintz et al. [21] suggested that LOS-P prediction allows a better understanding of risk factors associated with prolonged stays. Identifying such patients may direct hospitals towards more aggressive treatments and the provision of specialized care to prevent complications [34, 41].

Benefits associated with the cost dimension are estimates of financial values spent on hospitalization and cost reduction for the hospital. LOS-P forecast contributes to the hospital's strategic planning and guides medical care, reducing the length of the patient's stay and, consequently, hospitalization costs [29, 30]. Hospital management can bring several benefits to the hospital, being directly related to the other dimensions. Studies report management areas positively affected by LOS-P forecasts, such as resource allocation and planning [23, 26], patient flow management $[19,31]$, hospital bed management $[2,41]$, optimization of decision making $[18,22]$, and shift staff scheduling $[27,39]$. As for the benefits of measuring patient care quality, studies advocate the monitoring of hospital performance and the standardization of care across hospitals. Hospital performance may be assessed by measuring the effect of hospital-related variables in the LOS-P model [41] or by using predicted LOS values as reference [23], and the difference between the expected and actual LOS values as a service quality indicator [39]. The last dimension of benefits is related to the detection of variations in historical patterns due to changes in medical practices resulting from updating LOS-P models. Walczak and Scorpio [19] report that the use of neural network models makes solutions non-static; as medical practices evolve, the prediction model is quickly adapted through continuous learning based on new datasets.

Works included in this scoping review present some gaps related to the studied population and departments. Most LOS-P forecasting studies are focused on newborn patients; the analysis of child and adolescent patients constitutes a research opportunity. Studies are predominantly carried out at Neonatal Intensive Care units and hospitals or Psychiatric units. There is an opportunity to develop studies in Emergency departments and Pediatric Intensive Care units. Datasets including all pediatric ages and departments of pediatric hospitals are also needed to compare the performance between general and dedicated forecasting models. We reported a small number of multicenter studies and therefore identified such studies as a research opportunity. By doing it so, it would be possible to compare how the LOS-P forecasting would be impacted, for example, by patients from different locations and submitted to different treatments.

\section{Conclusions}

Our study aimed to identify works devoted to LOS-P forecasting through a scoping review of the literature. LOS forecasting is a tool to improve the management of resources in healthcare environments, helping organizations to cope with high demands and quality requirements. Although some literature review papers investigate the prediction of LOS in different environments and patient populations, we bridge a gap in the literature regarding reviews focusing on pediatric patients, a complex population with a high mortality risk that represents a challenge for hospital managers. Studies from our corpus rarely report the proposed forecasting models' real applicability, mostly indicating only qualitative benefits. The development of studies reporting the use of LOS-P forecasting models as tools for resource optimization through the qualitative and quantitative reporting of benefits remains a promising research direction.

This review article also has practical implications as it provides arguments to evaluate the applicability of different modeling techniques in forecasting the LOS-P in different environments and types of pediatric populations. That allows informing family members about the patient's expected discharge date, which is particularly critical for pediatric patients. Additionally, hospital resources' allocation and planning can be significantly improved by properly estimating the LOS-P. More 
assertive and precise LOS-P forecast models can significantly avoid waste of labor and materials shortages in hospitals, reducing costs and increasing efficiency.

Our study has some limitations. First, to ensure repeatability and allow a detailed analysis of the forecasting approaches reported in the literature, we limited our search to English databases. Second, performance comparisons were constrained by the studies' heterogeneity (e.g., different sample sizes, locations, methods, and performance metrics). Third, we do not analyze classification studies, which are concerned with classes of LOS instead of continuous forecasts. Fourth, CINAHL and Embase were not included in the search for studies as they cover essentially the same titles as Medline and Scopus, which could artificially inflate the initial count of articles. However, those databases provide unique indexing and citations that could have led to studies not retrieved in the four databases selected. Fifth, authors of articles in our corpus were not contacted to identify further related studies not discovered in the database searches. Finally, since the age range of pediatric patients varies in the literature, we included all studies that defined their population as pediatric, ranging from newborns to young adults.

\section{Supplementary Information}

The online version contains supplementary material available at https://doi. org/10.1186/s12913-021-06912-4.

\section{Additional file 1. \\ Additional file 2. \\ Additional file 3 .}

\section{Acknowledgements}

Not applicable.

\section{Authors' contributions}

NM, FF and MR contributed to the conception and design of the study. NM, $F F$, and MR contributed to the analysis and interpretation of the extracted data. NM and FF were major contributors in writing the manuscript. GT critically reviewed the manuscript for relevant academic content. All authors read and approved the final manuscript.

\section{Funding}

The author(s) received no specific funding for this work.

\section{Availability of data and materials}

All data generated or analyzed during this study are included in this published article.

\section{Declarations}

Ethics approval and consent to participate

Not applicable.

\section{Consent for publication}

Not applicable.

\section{Competing interests}

The authors declare that they have no competing interests.

\section{Author details}

${ }^{1}$ Department of Industrial Engineering, Universidade Federal do Rio Grande do Sul, Av. Osvaldo Aranha, 99, $5^{\circ}$ andar, Porto Alegre 90035-190, Brazil. ${ }^{2}$ Center of Engineering, Universidade Federal do Semi-Árido, Rua Francisco Mota Bairro, 572 - Pres. Costa e Silva, Mossoró, RN 59625-900, Brazil. ${ }^{3}$ Department of Mechanical Engineering, The University of Melbourne, Melbourne, Australia. ${ }^{4}$ IAE Business School, Universidad Austral, Buenos Aires, Argentina. ${ }^{5}$ Department of Industrial Engineering, Universidade Federal de Santa Catarina, Campus Universitário Reitor João David Ferreira Lima, s/nº Florianópolis, SC 88040-900, Brazil.

Received: 1 March 2021 Accepted: 9 August 2021

Published online: 08 September 2021

\section{References}

1. Kampstra Na, Zipfel N, van der Nat PB, et al. Health outcomes measurement and organizational readiness support quality improvement: a systematic review. BMC Health Serv Res. 2018;18:1005. https://doi.org/10.1186/s12913018-3828-9.

2. $M a F$, Yu L, Ye L, Yao DD, Zhuang W. Length-of-Stay Prediction for Pediatric Patients with Respiratory Diseases Using Decision Tree Methods. IEEE J Biomed Health Inform. 2020;24(9):2651-62. https://doi.org/10.1109/jbhi.202 0.2973285 (included in the corpus).

3. Leon SC, Snowden J, Bryant FB, Lyons JS. The hospital as predictor of children's and adolescents' length of stay. J Am Acad Child Adolesc Psychiatry. 2006;45(3):322-8. https://doi.org/10.1097/01.chi.0000194565.7853 $6 . \mathrm{bb}$ (included in the corpus).

4. Simon TD, Berry J, Feudtner C, Stone BL, Sheng X, Bratton SL, et al. Children with complex chronic conditions in inpatient hospital settings in the United States. Pediatrics. 2010;126(4):647-55. https://doi.org/10.1542/peds.2009-32 66.

5. Lemkin DL, Stryckman B, Klein JE, Custer JW, Maranda L, Wood KE, et al. Integrating a safety smart list into the electronic health record decreases intensive care unit length of stay and cost. J Crit Care. 2019;57:246-52. https://doi.org/10.1016/j.jcrc.2019.09.016.

6. Lisk R, Uddin M, Parbhoo A, Yeong K, Fluck D, Sharma P, et al. Predictive model of length of stay in hospital among older patients. Aging Clin Exp Res. 2019;31(7):993-9. https://doi.org/10.1007/s40520-018-1033-7.

7. Chen $\mathrm{CH}$, Hsieh JG, Cheng SL, Lin YL, Lin PH, Jeng JH. Early short-term prediction of emergency department length of stay using natural language processing for low-acuity outpatients. Am J Emerg Med. 2020;38(11):236873. https://doi.org/10.1016/j.ajem.2020.03.019.

8. Almashrafi A, Elmontsri M, Aylin P. Systematic review of factors influencing length of stay in ICU after adult cardiac surgery. BMC Health Serv Res. 2016; 16(1):318. https://doi.org/10.1186/s12913-016-1591-3.

9. Peres IT, Hamacher S, Oliveira FLC, Thomé AMT, Bozza FA. What factors predict length of stay in the intensive care unit? Systematic review and meta-analysis. J Crit Care. 2020;60:183-94. https://doi.org/10.1016/j.jcrc.2020. 08.003.

10. Atashi A, Verburg IW, Karim H, Miri M, Abu-Hanna A, de Jonge E, et al. Models to predict length of stay in the Intensive Care Unit after coronary artery bypass grafting: a systematic review. J Cardiovasc Surg. 2018;59(3): 471-82. https://doi.org/10.23736/S0021-9509.18.09847-6.

11. Hussain A, Dunn KW. Predicting length of stay in thermal burns: a systematic review of prognostic factors. Burns. 2013;39(7):1331-40. https:// doi.org/10.1016/j.burns.2013.04.026.

12. Lu M, Sajobi T, Lucyk K, Lorenzetti D, Quan H. Systematic review of risk adjustment models of hospital length of stay (LOS). Med Care. 2015;53(4): 355-65. https://doi.org/10.1097/mlr.0000000000000317.

13. Verburg IWM, Atashi A, Eslami S, Holman R, Abu-Hanna A, de Jonge E, et al. Which models can I use to predict adult ICU length of stay? A systematic review. Crit Care Med. 2017;45(2):e222-31. https://doi.org/10.1097/ccm. 0000000000002054

14. Seaton SE, Barker L, Jenkins D, Draper ES, Abrams KR, Manktelow BN. What factors predict length of stay in a neonatal unit: a systematic review. BMJ Open. 2016;6(10):e010466. https://doi.org/10.1136/bmjopen-2015-010466.

15. Arksey H, O'Malley L. Scoping studies: towards a methodological framework. Int J Soc Res Methodol. 2005;8(1):19-32. https://doi.org/10.1080/1364557032 000119616.

16. Tortorella GL, Fogliatto FS, Mac Cawley Vergara A, Vassolo R, Sawhney R. Healthcare 4.0: trends, challenges and research directions. Prod Plan 
Control. 2020;31(15):1245-60. https://doi.org/10.1080/09537287.2019.170222 6.

17. Tricco AC, Lillie E, Zarin W, O'Brien KK, Colquhoun H, Levac D, et al. PRISMA extension for scoping reviews (PRISMA-SCR): checklist and explanation. Ann Intern Med. 2018;169(7):467-73. https://doi.org/10.7326/M18-0850.

18. Walsh P, Cunningham P, Rothenberg SJ, O'Doherty S, Hoey H, Healy R. An artificial neural network ensemble to predict disposition and length of stay in children presenting with bronchiolitis. Eur J Emerg Med. 2004;11(5):25964. https://doi.org/10.1097/00063110-200,410,000-00004 (included in the corpus).

19. Walczak S, Scorpio RJ. Predicting pediatric length of stay and acuity of care in the first ten minutes with artificial neural networks. Pediatr Crit Care Med. 2000;1 (1):42-7. https://doi.org/10.1097/00130478-200,007,000-00008 (included in the corpus).

20. Paul M, Partridge J, Barrett-Reis B, Ahmad KA, Machiraju P, Jayapalan H, et al. Metabolic Acidosis in Preterm Infants is Associated with a Longer Length of Stay in the Neonatal Intensive Care Unit. PharmacoEconomics-Open. 2020; 4(3):541-7. https://doi.org/10.1007/s41669-020-00194-y (included in the corpus).

21. Hintz SR, Bann CM, Ambalavanan N, Cotten CM, Das A, Higgins RD. Predicting time to hospital discharge for extremely preterm infants. Pediatrics. 2010;125(1):e146-54. https://doi.org/10.1542/peds.2009-0810 (included in the corpus).

22. Jeremic, A., \& Tan, K. (2008). Predicting the length of stay for neonates using heart-rate Markov models. In 2008 30th Annual International Conference of the IEEE Engineering in Medicine and Biology Society, 2008, p. 2912-2915. DOI: https://doi.org/10.1109/IEMBS.2008.4649812. (included in the corpus)

23. Pepler FT, Uys DW, Nel DG. Predicting mortality and length-of-stay for neonatal admissions to private hospital neonatal intensive care units: a Southern African retrospective study. Afr Health Sci. 2012;12(2):166-73. https://doi.org/10.4314/ahs.v12i2.14 (included in the corpus).

24. Khoshnood B, Lee KS, Corpuz M, Koetting M, Hsieh HL, Kim Bl. Models for determining cost of care and length of stay in neonatal intensive care units. Int J Technol Assess Health Care. 1996;12(1):62-71. https://doi.org/10.1017/ s0266462300009399 (included in the corpus).

25. Pearlman SA, Stachecki S, Aussprung HL, Raval N. Predicting length of hospitalization of sick neonates from their initial status. Clin Pediatr. 1992; 31(7):391-3. https://doi.org/10.1177/000992289203100702 (included in the corpus).

26. Lee HC, Bennett MV, Schulman J, Gould JB, Profit J. Estimating length of stay by patient type in the neonatal intensive care unit. Am J Perinatol. 2016;33(08):751-7. https://doi.org/10.1055/s-0036-1,572,433 (included in the corpus).

27. Bender GJ, Koestler D, Ombao H, McCourt M, Alskinis B, Rubin LP, et al. Neonatal intensive care unit: predictive models for length of stay. J Perinatol. 2013;33(2):147-53. https://doi.org/10.1038/jp.2012.62 (included in the corpus).

28. Rendina MC. The effect of telemedicine on neonatal intensive care unit length of stay in very low birthweight infants. In Proceedings of the AMIA Symposium (p. 111). Am Med Inform Assoc. 1998; (included in the corpus).

29. Bannwart D, Rebello CM, Sadeck, L. d SR, Pontes MD, Ramos JLA, Leone CR. Prediction of length of hospital stay in neonatal units for very low birth weight infants. J Perinatol. 1999;19(2):92-6. https://doi.org/10.1038/sj.jp.72 00134 (included in the corpus).

30. Marshall G, Luque MJ, Gonzalez A, Musante G, Tapia JL. Center variability in risk of adjusted length of stay for very low birth weight infants in the Neocosur South American Network. J Pediatr. 2012;88(6):524-30. https://doi. org/10.2223/jped.2234 (included in the corpus).

31. Levin SR, Harley ET, Fackler JC, Lehmann CU, Custer JW, France D, et al. Real-time forecasting of pediatric intensive care unit length of stay using computerized provider orders. Crit Care Med. 2012;40(11):3058-64. https:// doi.org/10.1097/ccm.0b013e31825bc399 (included in the corpus).

32. Anderson JB, Beekman RH III, Border WL, Kalkwarf HJ, Khoury PR, Uzark K, et al. Lower weight-for-age $z$ score adversely affects hospital length of stay after the bidirectional Glenn procedure in 100 infants with a single ventricle. J Thorac Cardiovasc Surg. 2009;138(2):397-404. https://doi.org/10.1016/j. jtcvs.2009.02.033 (included in the corpus).

33. Pastura PSVC, Land MG, Santoro-Lopes G. Predictive model for the length of hospital stay of children with hematologic malignancies, neutropenia, and presumed infection. J Pediatr Hematol Oncol. 2004;26(12):813-6 (included in the corpus).
34. Kavanaugh B, Studeny J, Cancilliere MK, Holler KA. Neurocognitive predictors of length of stay within a children's psychiatric inpatient program. Child Neuropsychology. 2020;26(1):129-36. https://doi.org/10.1 080/09297049.2019.1617843 (included in the corpus).

35. Gold J, Shera D, Clarkson JR, B. Private psychiatric hospitalization of children: predictors of length of stay. J Am Acad Child Adolesc Psychiatry. 1993;32(1): 135-43. https://doi.org/10.1097/00004583-199,301,000-00020 (included in the corpus).

36. Höger C, Zieger H, Presting G, Witte-Lakemann G, Specht F, Rothenberger A. Predictors of length of stay in inpatient child and adolescent psychiatry: failure to validate an evidence-based model. Eur Child Adolesc Psychiatry. 2002;1 1(6):281-8. https://doi.org/10.1007/s00787-002-0290-2 (included in the corpus).

37. Stewart SL, Kam C, Baiden P. Predicting length of stay and readmission for psychiatric inpatient youth admitted to adult mental health beds in Ontario, Canada. Child Adolesc Mental Health. 2014;19(2):115-21. https://doi.org/1 $0.1111 /$ camh. 12022 (included in the corpus).

38. Browning DL. Psychiatric ward behavior and length of stay in adolescent and young adult inpatients: A developmental approach to prediction. J Consult Clin Psychol. 1986;54(2):227-30. https://doi.org/10.1037//0022-006x. 54.2.227 (included in the corpus).

39. Zernikow B, Holtmannspötter K, Michel E, Hornschuh F, Groote K, Hennecke KH. Predicting length-of-stay in preterm neonates. Eur J Pediatr. 1999;158(1): 59-62. https://doi.org/10.1007/s004310051010 (included in the corpus).

40. Parkman SE, Woods SL. Infants who have undergone cardiac surgery: what can we learn about lengths of stay in the hospital and presence of complications? J Pediatr Nurs. 2005;20(6):430-40. https://doi.org/10.1016/j. pedn.2005.03.013 (included in the corpus).

41. Lee AH, Gracey M, Wang K, Yau KK. A robustified modeling approach to analyze pediatric length of stay. Ann Epidemiol. 2005;15(9):673-7. https:// doi.org/10.1016/j.annepidem.2004.10.001 (included in the corpus).

42. Balan S, Gawade T, Tasgaonkar A. A Machine Learning Approach for Prediction of Length of Stay for the Kid's Inpatient Database. In: 2019 IEEE International Conference on Big Data (Big Data); 2019. p. 5980-2. https:// doi.org/10.1109/EMBC44109.2020.9175889. (included in the corpus).

43. Nagarsheth KH, Gandhi SS, Heidel RE, Kurek SJ, Angel C. A mathematical model to predict length of stay in pediatric ATV accident victims. J Surg Res. 2011;171(1):28-30. https://doi.org/10.1016/j.jss.2011.03.063 (included in the corpus).

44. Kotz N, Read CB, Balakrishnan N, et al. Encyclopedia of Statistical Sciences. New York: John Wiley; 2004. https://doi.org/10.1002/0471667196.

45. Bishop CM. Pattern Recognition and Machine Learning. Berlin: SpringerVerlag; 2006. ISBN: 978-0-387-31,073-2

\section{Publisher's Note}

Springer Nature remains neutral with regard to jurisdictional claims in published maps and institutional affiliations.

Ready to submit your research? Choose BMC and benefit from:

- fast, convenient online submission

- thorough peer review by experienced researchers in your field

- rapid publication on acceptance

- support for research data, including large and complex data types

- gold Open Access which fosters wider collaboration and increased citations

- maximum visibility for your research: over $100 \mathrm{M}$ website views per year

At $\mathrm{BMC}$, research is always in progress.

Learn more biomedcentral.com/submission 